\title{
Gerenciamento de resíduos madeireiros produzidos em uma marcenaria do Tribunal de Justiça de Pernambuco
}

As políticas ambientais atualmente estão exercendo uma forte pressão sobre todos os segmentos geradores de resíduos sólidos. Dentre esses, está à indústria moveleira, pois produz grande quantidade e diversidade de resíduos de madeira, cuja exploração e desperdício desencadeiam uma série de impactos negativos para o meio ambiente e para a saúde pública. Este trabalho teve por objetivo, através de estudo realizado em uma oficina de marcenaria, localizada na cidade do Recife-PE, pertencente ao Tribunal de Justiça de Pernambuco, propor um sistema de gerenciamento de resíduos madeireiros gerados nessa oficina em conformidade com as leis e resoluções vigentes, com finalidade de minimizar os impactos ambientais negativos oriundos dos resíduos produzidos neste setor. A metodologia utilizada se fez através da coleta de dados por meio de observação direta, entrevista e aplicação de questionário contendo questões referentes aos tipos e desperdícios de matérias-primas, equipamentos usualmente utilizados, cadeia produtiva e os tipos de resíduos gerados nesse processo. Os compensados, os painéis de divisórias e de MDF são a principal matéria-prima da marcenaria. Predominou-se a compra de compensados (61\%), seguido de painéis de divisórias $(30 \%)$ e MDF (9\%). Os equipamentos utilizados foram a serra circular, a plaina, a lixadeira e a furadeira. Os resíduos gerados durante o processo produtivo foram o retraço (33\%), a serragem (33\%), o cavaco $(16,67 \%)$ e a maravalha $(16,67 \%)$. Verificou-se que o modelo atual de gerenciamento de resíduos era a doação, faltando ações para a redução de geração e de seu aproveitamento. O resultado mostrou que o nível de desperdício da matéria-prima em forma de resíduos é bastante significativo, girando em torno de $24,5 \%$.

\section{Management of wood residues produced in a joinery of the Court of Justice of Pernambuco}

Environmental policies are currently putting strong pressure on all segments of solid waste generation. Among these, there is the industry furniture, since it produces a large quantity and diversity of wood residues, whose exploitation and waste of which trigger a series of negative impacts for the environment and public health. This research aimed, through a study carried out in a joinery workshop, located in the city of Recife-PE, belonging to the Court of Justice of Pernambuco, to propose a system of management of wood residues generated in this workshop in compliance with the laws and resolution in force, in order to minimize negative environmental impacts from the waste produced in this sector. The methodology used was made through data collection through direct observation, interview and application of a questionnaire containing questions regarding types and waste of raw materials, equipment usually used, the production chain and types of waste generated in this process. Plywood, partition panels and MDF are the main raw material of joinery. The purchase of plywood was predominant $(61 \%)$, followed by partition panels $(30 \%)$ and MDF $(9 \%)$. The equipment used where the circular saw, the planer, the sander and the drill. The waste generated during the production process were retracts $(33,33 \%)$, sawdust $(33,33 \%)$, the wood ships $(16,67 \%)$ and wood shavings (16,67\%). It was found that the current model of woodworking waste management was the donation, lacking actions to reduce generation and its use. The result showed that the level of waste of the raw material in the form waste is quite significant, around $24,5 \%$.

Keywords: Joinery; Wood waste; Environment; Management.

Topic: Desenvolvimento, Sustentabilidade e Meio Ambiente

Reviewed anonymously in the process of blind peer.

Edson Santos Agra (iD

Instituto de Tecnologia de Pernambuco, Brasil

http://lattes.cnpq.br/7429335209813183

http://orcid.org/0000-0001-6663-3351

santoagra@hotmail.com

Eduardo Antonio Maia Lins (iD)

Instituto Federal de Pernambuco, Brasil

http://lattes.cnpq.br/6148771863554184

http://orcid.org/0000-0002-9108-4179

eduardomaialins@gmail.com

Daniele de Castro Pessoa de Melo (iD

Instituto Tecnológico de Pernambuco, Brasil

http://lattes.cnpq.br/4010783198064867

http://orcid.org/0000-0003-4058-092X

danielecastro3@hotmail.com

a

DOI: 10.6008/CBPC2179-6858.2021.003.0038
Received: 03/03/2021

Approved: 26/03/2021

Cecília Maria Mota Silva Lins

Universidade Federal Rural de Pernambuco, Brasil

http://lattes.cnpq.br/4861195143983172

cecilia.lins@gmail.com

Wanderson dos Santos Sousa

Instituto tecnológico de Pernambuco, Brasil

http://lattes.cnpq.br/2702592671280843

wanderson.santos@itep.br

Referencing this:

AGRA, E. S.; LINS, E. A. M.; MELO, D. C. P.; LINS, C. M. M. S.; SOUSA, W. S.. Gerenciamento de resíduos madeireiros produzidos em uma marcenaria do Tribunal de Justiça de Pernambuco. Revista Ibero Americana de Ciências Ambientais, v.12, n.3, p.469-480, 2021. DOI: http://doi.org/10.6008/CBPC2179-6858.2021.003.0038 


\section{INTRODUÇÃO}

De acordo com a Associação Brasileira de Indústria de Móveis (Abimóvel), a produção de móveis foi de 34,7 milhões de peças em junho de 2020 , resultado $15,3 \%$ maior que o de maio. No ano, de janeiro a junho, houve alta de 5,5\% na produção de volumes, segundo dados do Instituto Brasileiro de Geografia e Estatística (IBGE). No acumulado dos doze meses o crescimento foi de 9,3\%.

Toda cadeia produtiva tem como consequência direta a geração de resíduos, logo não seria diferente nas indústrias madeireiras, independentemente da forma de processamento, seja ele primário ou secundário. Portanto, o setor mobiliário, em seu processo produtivo, precisa assegurar a procura de variáveis que contribuam para a mitigação das causas geradoras desses resíduos. Como se observa, os resíduos sólidos, em todas as suas formas, são um dos maiores desafios da atualidade, tendo em vista que sua crescente produção no planeta está diretamente relacionada ao crescimento demográfico e o desenvolvimento econômico. Sendo assim, é de fundamental importância o gerenciamento desses resíduos, para se estabelecer o controle da quantidade dos produtos e a destinação final adequada para cada tipo de resíduo, evitando-se o desperdício e a degradação ambiental (NASCIMENTO, 2009). Além disso, empresas ambientalmente responsáveis são cada vez mais valorizadas e bem vistas pelos clientes investidores, o que significa que o país vem acompanhando a tendência mundial de conscientização ecológica (GOMES et al., 2015).

Dentre os tipos diversos de resíduos produzidos nas atividades antrópicas estão os resíduos oriundos das marcenarias que são aqueles resultantes direta ou indiretamente do beneficiamento da madeira, tais como: tocos, pontas, aparas, peças com defeito, serragem, pó, entre outros. Esses resíduos por serem constituídos de diferentes tamanhos e formas podem ser perigosos quando dispostos de forma inadequada.

Desta forma, verifica-se a relevância que é o estudo do gerenciamento de resíduos madeireiros produzidos pela marcenaria do Tribunal de Justiça de Pernambuco, principalmente no tocante à análise dos dados obtidos e informações com a finalidade de definir estratégias de redução/eliminação desses resíduos na fonte, bem como melhorar a destinação dos mesmos, quando gerados.

\section{MATERIAIS E MÉTODOS}

\section{Caracterização da área de estudo}

Este estudo foi desenvolvido na marcenaria do Tribunal de Justiça de Pernambuco. Suas atividades, tanto na região metropolitana do Recife como nos municípios do interior do Estado, envolvem além de intervenções de manutenção preventiva e corretiva, consertos de móveis e confecção de mobiliários, tais como: birôs, gaveteiros, estações de trabalho, bancadas de serviços e armários destinados aos Fóruns, Juizados, Diretorias administrativas e demais departamentos pertencentes ao TJPE. Os desenhos dos produtos que serão confeccionados (Plantas gráficas) são projetados pelo Departamento de Engenhar e Arquitetura (DEA) do TJPE e o planejamento e execução desses produtos são realizados de acordo com a solicitação de pedidos que são efetuados através de ofícios via aplicativo utilizado em diversos órgãos 
públicos, inclusive no TJPE, que é o SEI (Sistema Eletrônico de Informações) que foi desenvolvido pelo Tribunal Regional Federal da 4a Região (TRF4). É uma ferramenta de gestão de documentos e processos eletrônicos, e tem como objetivo promover a eficiência administrativa no âmbito do serviço público. Segue abaixo, Figura 1, a foto da marcenaria objeto deste estudo.
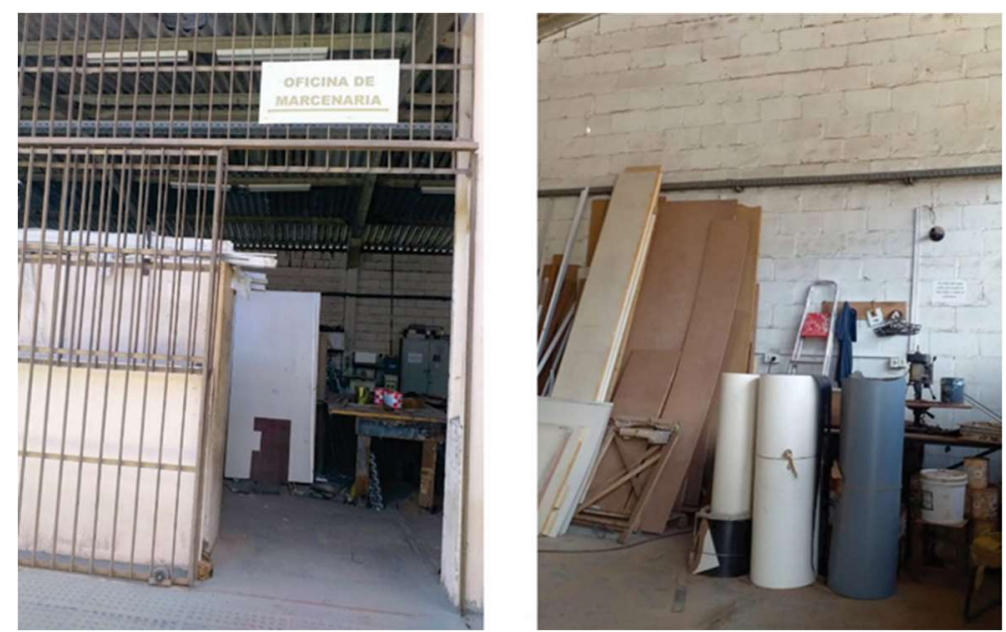

Figura 1: Marcenaria do Tribunal de Justiça de Pernambuco.

O presente trabalho utilizou pesquisa bibliográfica em formato de pesquisa qualitativa, bem como documentação cedida pela Gerência de Manutenção do TJPE, a qual responde pela Unidade de Marcenaria (localizada no Recife-PE), objeto deste estudo.

Quantos aos objetivos, a pesquisa é exploratória, pois analisa os processos com o intuito de encontrar possíveis causas de falhas. Sendo assim, procura-se propor soluções de melhorias para reduzir ou eliminar a ocorrências de falhas. A pesquisa exploratória tem como finalidade analisar problemas, a fim de descobrir novas práticas de melhorias de produtos ou processos.

\section{Coleta de dados}

Para avaliação da geração de resíduos madeireiros na oficina de marcenaria do TJPE, foi realizada uma coleta de dados, os quais foram obtidos através da aplicação de questionário no local, com visitas, durante o período de junho a julho de 2020. O questionário, representado na Figura 2, foi adaptado com base na pesquisa de Mendoza et al. (2010). O mesmo foi subdividido em 05 etapas fundamentais. Na primeira, foram coletados os dados cadastrais da marcenaria e do entrevistado; na segunda, os dados referentes aos tipos de matérias-primas utilizados; na terceira, os dados sobre equipamentos usados frequentemente na marcenaria; na quarta, sobre o modelo de produção dos móveis; e, na quinta parte, foram coletados os tipos de resíduos madeireiros, os equipamentos geradores desses resíduos e sobre seu destino final.

A inserção das partes segunda a quarta nesse questionário teve como objetivo evidenciar uma melhor caracterização da marcenaria do TJPE, visando, primordialmente, ao conhecimento das matériasprimas utilizadas; maquinário presente e produção mensal de móveis; para uma melhor compreensão e interpretação dos dados sobre a geração dos resíduos madeireiros. Para a quantificação foram coletados, 
mensalmente, todos os resíduos gerados pela marcenaria. Os resíduos foram quantificados $\mathrm{em}^{3}$, utilizando-se um caixote de madeira com gabarito, cujas dimensões eram $1 \mathrm{~m} \times 1 \mathrm{~m} \times 1 \mathrm{~m}$.

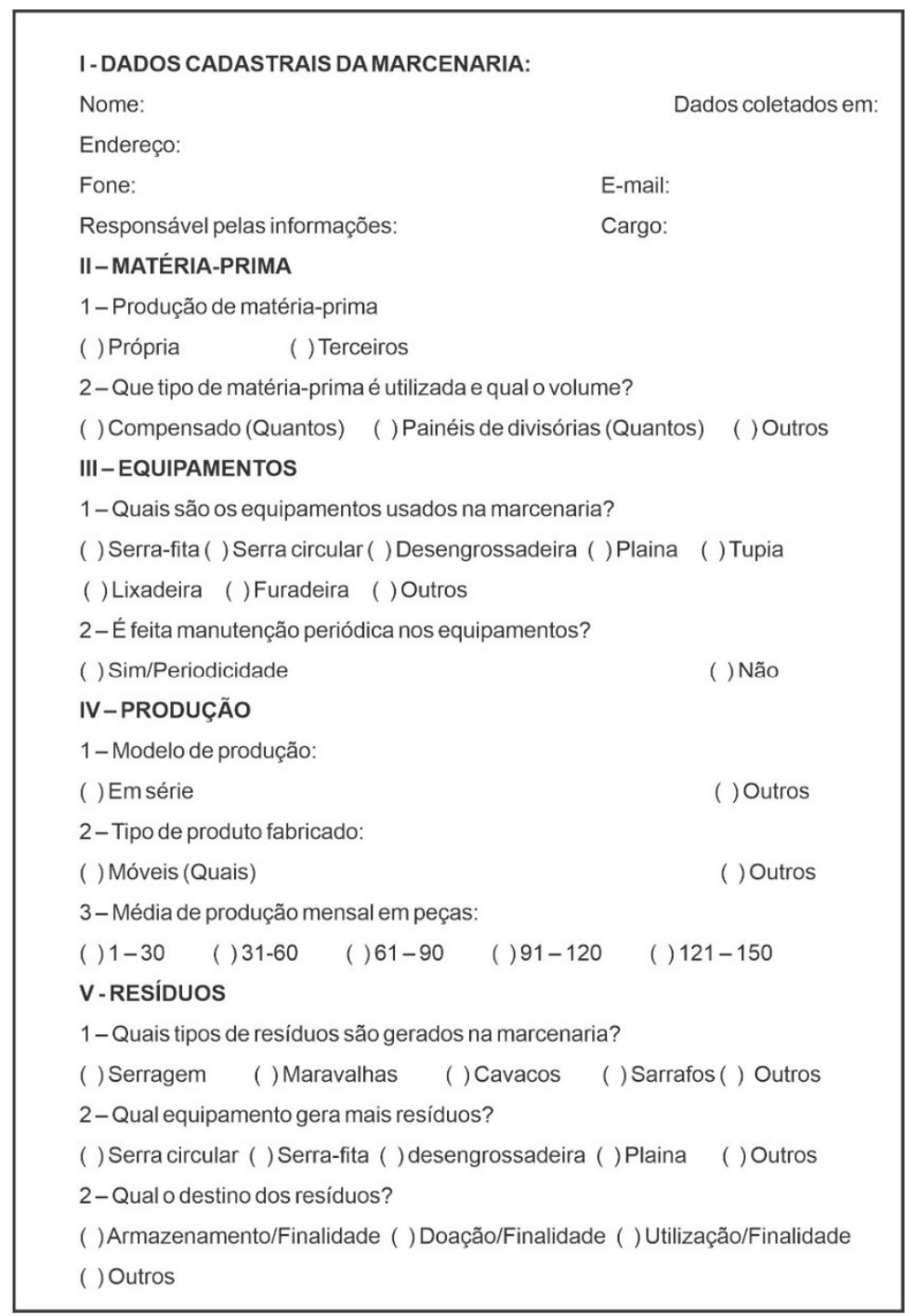

Figura 2: Questionário adaptado com base em Mendonza et al. (2010).

\section{Análise de dados}

De acordo com um autor em 2016, 'a análise tem como objetivo organizar e sumariar os dados de maneira que correspondam ao problema proposto para investigação'. É importante ressaltar que a marcenaria estudada não possui um histórico de quantidade de matérias-primas e tampouco de resíduos madeireiros produzidos em seus processos. Por conta disso, as quantidades apresentadas nessa seção são estimativas fornecidas pelo entrevistado.

\section{Cálculos de desperdícios de matéria-prima}

Com a finalidade de realizar os cálculos de desperdícios de matérias-primas no processo da marcenaria, estabeleceu-se um vínculo da matéria-prima utilizada com a quantidade de resíduos de madeira gerados, no ano de 2019, por meio da fórmula empregada em estudos de Caetano (2017). Dessa forma temse: 


$$
E=\left(1-\frac{r e s}{m p}\right) \times 100
$$

\section{RESULTADOS E DISCUSSÃO}

As principais matérias-primas utilizadas na marcenaria do TJPE para confecção dos produtos são os painéis de madeira reconstituída (Compensado, Painéis de divisórias e MDF) adquiridos através de certame licitatório. A modalidade de licitação foi o Pregão Eletrônico, à qual é utilizada para aquisição de bens e serviços comuns, em que a disputa pelo fornecimento é feita em sessão pública, por meio de propostas e lances, para classificação e habilitação do solicitante com a proposta de menor preço.

De acordo com o Sebrae (2017), os substitutos diretos e indiretos são geralmente produtos ou serviços semelhantes com preços menores, no caso de móveis planejados, caso da marcenaria do TJPE, é cada vez maior o uso de matérias-primas derivadas da madeira, uma vez que o custo da madeira maciça é maior e seu impacto no meio ambiente também.

Predominou-se, na marcenaria, a compra de compensados (61\%), seguido de painéis de divisórias (30\%) e em menor porcentagem painéis de MDF (9\%), conforme pode ser visto na Figura 03a.

Observa-se que Santos (2017) registra em seu estudo que as principais matérias-primas utilizadas na marcenaria da Universidade Federal de Sergipe (UFS) para confecção dos produtos são os painéis de madeira (MDF, MDP e compensado), adquiridos por meio de licitação realizada pelos pregoeiros do Departamento de Materiais - DRM, e que o MDF (Painel de Fibra de Média Densidade) está sendo o mais utilizado. Ao contrário da marcenaria do TJPE que utiliza o compensado como painel principal nas confecções de seus produtos.

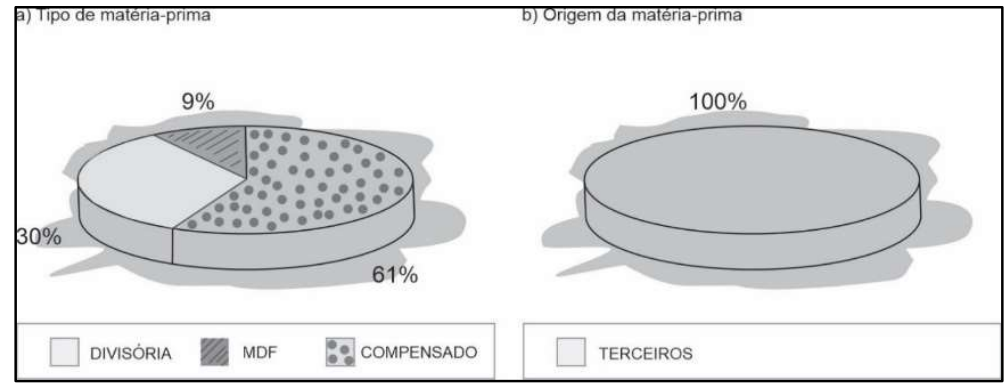

Figura 3: Matéria-prima, utilizada na marcenaria, adquirida a terceiros (fornecedores) através de licitação, na modalidade Pregão Eletrônico.

Os principais equipamentos presentes na marcenaria foram a serra circular, a plaina, a lixadeira e a furadeira, máquinas utilizadas que são evidenciadas, em porcentagem, na Figura 4. Os equipamentos são de origem nacional, não automatizada, de modelos antigos, utilizados entre 0 a 10 anos, conforme representação na Figura 5a. Ressaltando que a maioria dos equipamentos não recebia manutenção adequada, Figura $5 b$, conforme as recomendações dos fabricantes, o que refletia diretamente no aumento da geração de resíduos. 
A fabricação de móveis esteve sempre relacionada à geração de resíduos sólidos, principalmente nas etapas de beneficiamento da madeira. Neste contexto, o maquinário base utilizado pela marcenaria do Tribunal de Justiça de Pernambuco na cadeia produtiva, pode influenciar substancialmente na geração de resíduos, especificamente no que diz respeito à sua manutenção e tempo de uso.

Nolasco et al. (2014) relaciona, ainda, a geração de resíduos de madeira a qualidade da matériaprima e insumos; aos equipamentos; ferramentas, tecnologias utilizadas, mão-de-obra operacional e gerencial; design e/ou características do produto.

Alves et al. (2008) em estudo realizado na cidade de Viçosa-MG, encontraram resultados semelhantes em relação às máquinas utilizadas pelas marcenarias, que em sua totalidade utilizavam os seguintes equipamentos: desempenadeira (plaina), furadeira, lixadeira e serra circular. Máquinas estas também utilizadas na marcenaria do TJPE.

Santos (2017) observaram que as principais máquinas utilizadas nos processos produtivos dos móveis nas marcenarias de Montes Claros-MG foram: serra circular, furadeira, esmeril e lixadeira, o que significa uma equivalência, em termos de uso, de $75 \%$ com a marcenaria objeto deste estudo.

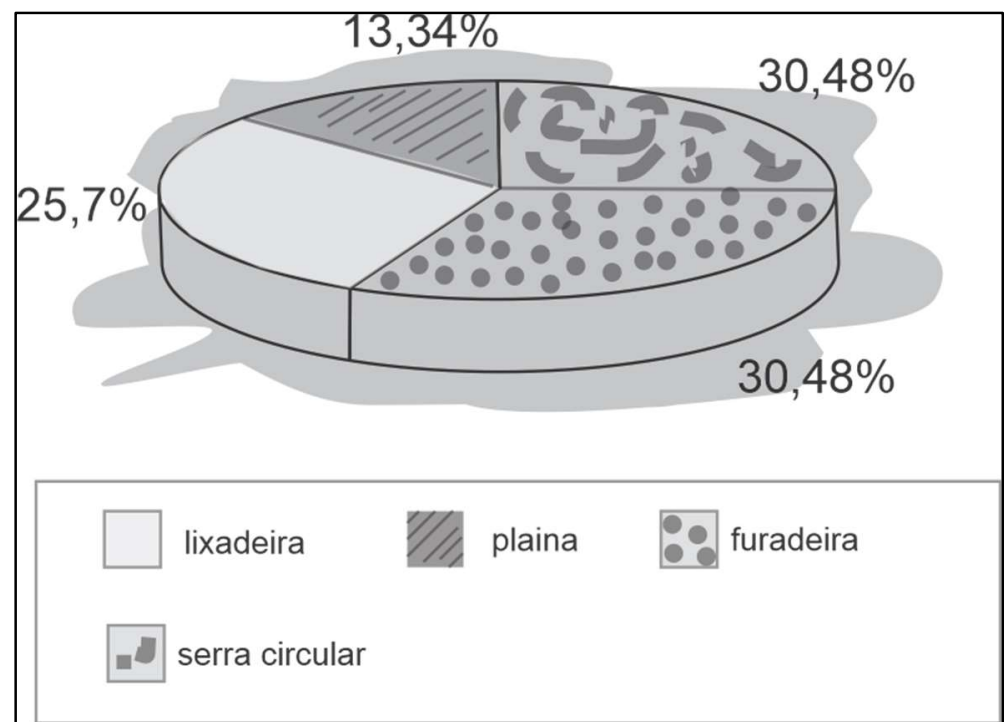

Figura 4: Porcentagem média de utilização na cadeia produtiva das principais máquinas.

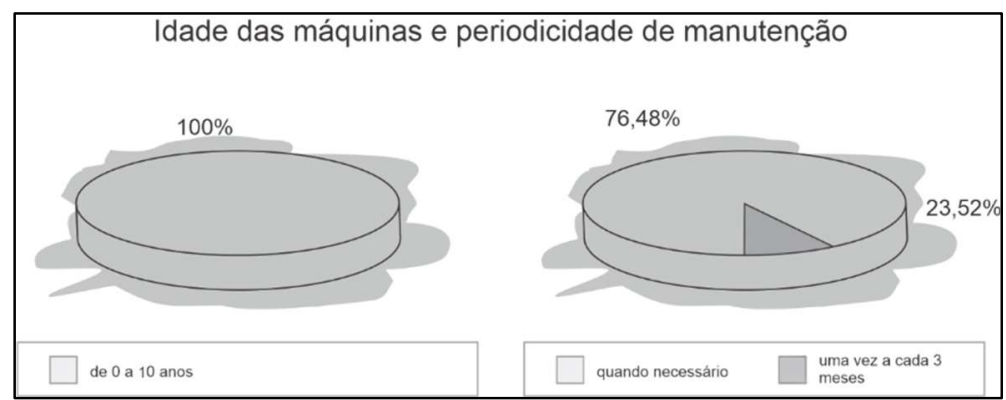

Figuras 5a e 5b: Idade das máquinas e periodicidade de manutenção.

Os móveis confeccionados pela Unidade de Marcenaria do TJPE são em média 14 unidades por mês. Dentre os móveis mais fabricados estão gaveteiros, Birôs e armários (em média 10 unidades por mês), estações de trabalho e bancadas de serviço (em média 04 unidades por mês), Figura 6a. Mantém uma linha de fabricação em média entre um e trinta móveis por mês, conforme mostrado na Figura 6b. 
Como não há comercialização de móveis, logo não há concorrência. Isso significa que a marcenaria destina sua produção exclusivamente para a demanda interna, porém, foi registrado durante o estudo a necessidade de otimização na cadeia produtiva no tocante a geração de resíduos madeireiros. Figura 06a e 06b.

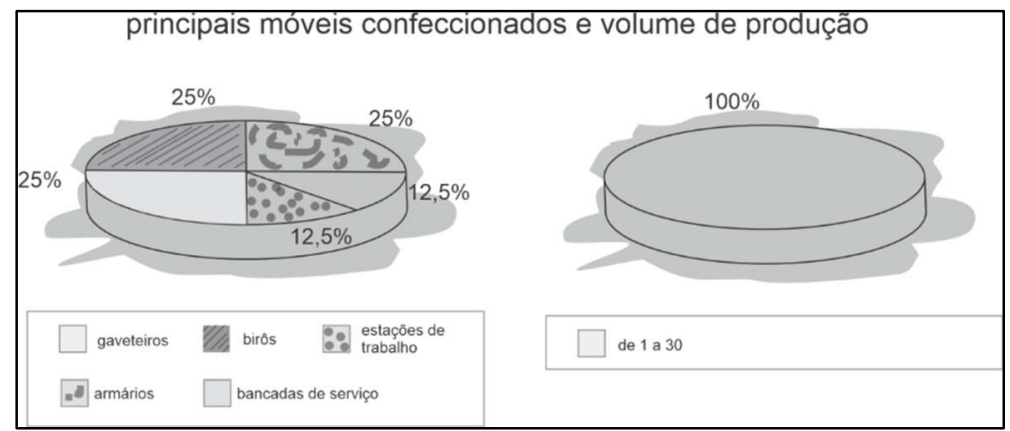

Figura 6: Principais indicadores de produção de móveis na marcenaria do Tribula de Justiça de Pernambuco.

Assim, substituindo-se os valores apresentados na tabela 1 (resíduos madeireiros) e na tabela 2 (matéria-prima) multiplicado por 12 (meses) na seguinte equação, encontra-se:

$$
E=\left(1-\frac{5,76}{23,52}\right) \times 100=75,5 \%
$$

Logo, a eficiência da marcenaria é de 75,5\% e o desperdício de matéria-prima em forma de resíduo gira em torno de 24,5\%, como apresentado na Figura 7.

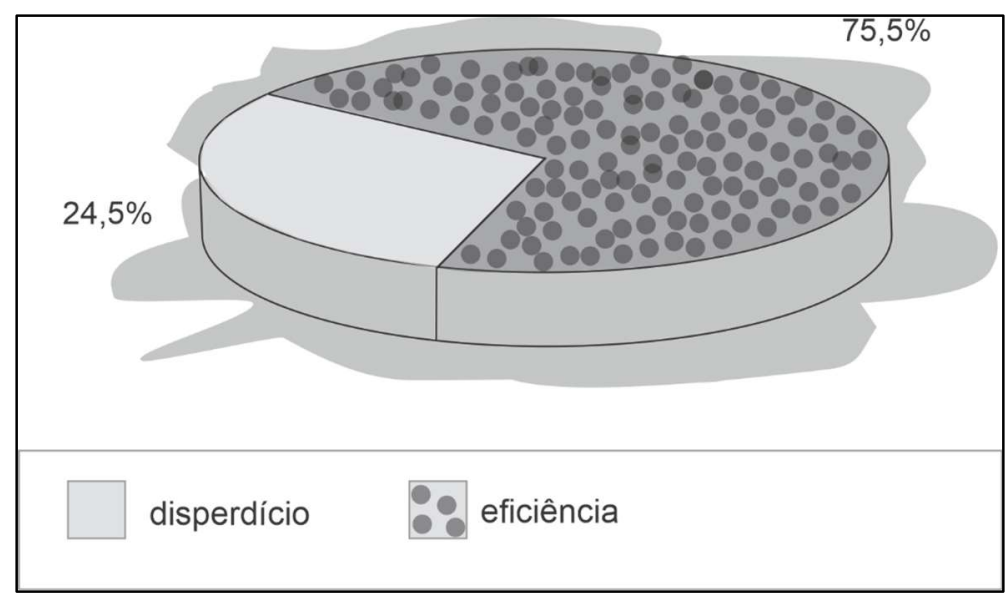

Figura 7: Gráfico da Perda da matéria-prima na forma de resíduo.

Segundo diagnosticado por Hillig et al. (2009), o aproveitamento da matéria-prima no processo produtivo pelas indústrias do polo moveleiro da Serra Gaúcha é em média de $66 \%$, sendo que os resíduos principais são de chapas de madeira aglomerada e MDF (médium density fiberboard), além da madeira serrada. Em todas as fases de transformação a madeira gera muitos resíduos, sendo que cerca de 40 a $60 \%$ do volume é aproveitado no final do processo. No tocante ao aproveitamento da matéria-prima pela marcenaria do TJPE, constatou-se um ganho considerável de 9,5\% a maior em relação ao polo moveleiro da Serra Gaúcha.

Como demonstração no gráfico, os dados apresentados permitem evidenciar que $24,5 \%$ de matéria prima se transformam em resíduos de madeira ao final do processo. Pôde-se observar que essa perda é significativa ao compará-la com estudos realizados por Caetano et al. (2017), em uma marcenaria de pequeno 
porte em Cariacica-ES, na qual se constatou uma perda superior a $20 \%$.

Como o estudo tem como foco principal abordar os resíduos madeireiros oriundos de a marcenaria do TJPE, o enfoque no processo produtivo se deu na própria oficina. A Figura 08 mostra os volumes estimados dos principais resíduos madeireiros gerados na fabricação de móveis, ou seja: retraços (33,33\%), serragem $(33,33 \%)$, cavaco $(16,67 \%)$ e maravalhas $(16,67 \%)$. Valores calculados com base nos dados fornecidos pelo entrevistado. As estimativas das quantidades produzidas mensalmente dos resíduos madeireiros no ano de 2019 e a quantidade mensal estimada da matéria-prima utilizada estão evidenciadas, respectivamente, nas tabelas 1 e 2, abaixo especificadas.

Tabela 1: Quantidade mensal estimada dos principais resíduos gerados.

\begin{tabular}{ccccc}
\hline $\begin{array}{c}\text { Principais } \\
\text { Resíduos }\end{array}$ & $\begin{array}{c}\text { Quantidade/mês } \\
\mathrm{kg} \text { (Massa) }\end{array}$ & $\begin{array}{c}\text { Percentual } \\
\% \text { (Massa) }\end{array}$ & $\begin{array}{c}\text { Quantidade/mês } \\
\mathrm{m}^{3} / \text { mêsVolume }\end{array}$ & $\begin{array}{c}\text { Percentual } \\
\% \text { (Volume) }\end{array}$ \\
\hline retraço & 50 & 33,33 & 0,18 & 37,50 \\
serragem & 50 & 33,33 & 0,16 & 33,33 \\
cavaco & 25 & 16,67 & 0,07 & 14,59 \\
maravalha & 25 & 16,67 & 0,07 & 14,58 \\
total & 150 & 100 & 0,48 & 100 \\
\hline
\end{tabular}

Tabela 2: Quantidade mensal estimada das principais matérias-primas usadas no processo de fabricação de móveis na marcenaria do TJPE.

\begin{tabular}{ccccc}
\hline $\begin{array}{c}\text { Matéria-prima } \\
\text { usada }\end{array}$ & $\begin{array}{c}\text { Quantidade/mês } \\
\text { kg (Massa) }\end{array}$ & $\begin{array}{c}\text { Percentual } \\
\% \text { (Massa) }\end{array}$ & $\begin{array}{c}\text { Quantidade } \\
\mathrm{m}^{3 / \text { mêsVolume }}\end{array}$ & $\begin{array}{c}\text { Percentual } \\
\% \text { (Volume) }\end{array}$ \\
\hline $\begin{array}{c}\text { compensado } \\
\text { MDF }\end{array}$ & 211,2 & 34,53 & 0,36 & 18,37 \\
$\begin{array}{c}\text { painéis de } \\
\text { divisória } \\
\text { Total }\end{array}$ & 312,4 & 51,08 & 1,41 & 71,93 \\
& 611,6 & 14,39 & 0,19 & 9,7 \\
\hline
\end{tabular}

Já nos estudos realizados por Mendoza et al. (2010) em marcenarias na região de Viçosa-MG destaca que os principais resíduos gerados foram: serragem/pó (36\%, 17\%), sarrafo (25,3\%), maravalha (23,4\%) e cavaco $(12,77 \%)$.

Ainda segundo Lopes (2016) em estudos realizados em pequenas indústrias de produtos madeireiros em Piracicaba-SP, ressalta que os principais resíduos foram: 26,39\% de resíduos finos (maravalha, serragem e pó); $12,64 \%$ de peças de reaproveitamento (retraços) e 5,82 de resíduos grossos (destopos, refilos e aparas - cavacos). Os estudos realizados por ambos obtiveram resultados diferentes daqueles encontrados na marcenaria do TJPE.

Ainda sobre o assunto Maffessoni et al. (2012) ressaltam que estes resíduos têm variações de quantidade conforme os processos produtivos utilizados pelas empresas, assim como o tipo e o estado do maquinário, muitas vezes velho com funcionamento prejudicado, e ainda por meio dos projetos de produtos mal pensados, com dimensões das peças com aproveitamento ruim para o material. 
A geração de resíduos de madeira está relacionada à qualidade da matéria-prima e insumos; aos equipamentos; ferramentas, tecnologias utilizadas; mão-de-obra operacional e gerencial; design e/ou características do produto (NOLASCO et al., 2014).

Lopes (2016) em estudo sobre marcenaria observa que, as principais ações identificadas para aprimorar o gerenciamento dos resíduos seriam em relação aos equipamentos, adotando sua manutenção preventiva realizada através de estabelecimento de programa de afiação e troca de peças a ser realizado periodicamente. Este tipo de ação visa à diminuição da geração de resíduos.

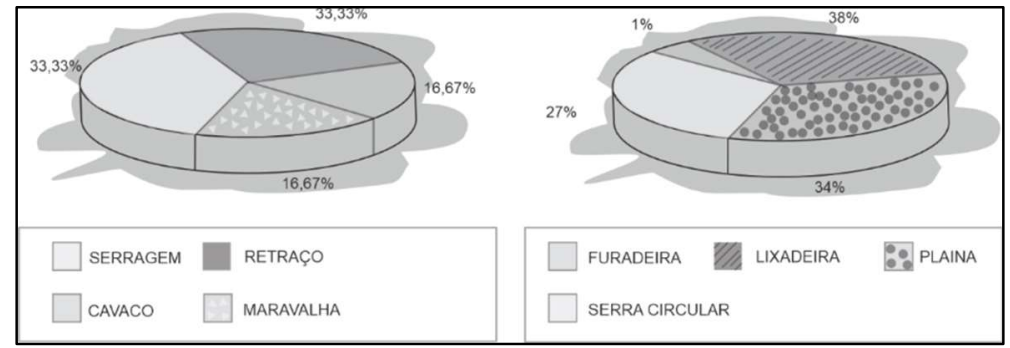

Figuras 8a e 8b: Principais tipos de resíduos gerados e respectivas máquinas geradoras.

Na Figura 9 são apresentados os principais destinos dos resíduos gerados pela oficina de marcenaria do Tribunal de Justiça de Pernambuco que doava seus resíduos, como forma de gerenciamento, para a Cooperativa Bola na Rede, situada no bairro da Guabiraba, os quais se destinavam a matéria-prima de fornos e padarias $(41,18 \%)$, forração para criação de frangos $(41,17 \%)$, consumo doméstico $(17,65 \%)$.

Com base na entrevista, constatou-se que não havia preocupação quanto a maior agregação de valor ao resíduo gerado ou da dimensão de danos ambientais que estes resíduos poderiam causar, caso fossem dispostos de forma inadequada, confirmando-se, assim, a baixa percepção ambiental dos colaboradores que compõem o quadro da marcenaria.

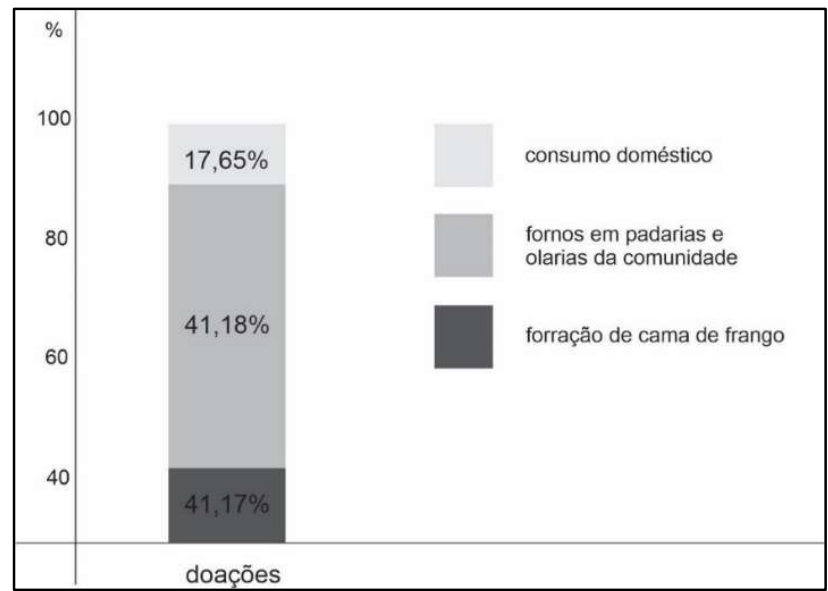

Figura 9: Principais usos, pela Cooperativa, dos resíduos gerados.

Com base no que foi visto ao longo deste trabalho, propõem-se as seguintes medidas potencializadoras do melhor aproveitamento dos resíduos gerados na marcenaria do TJPE: Fabricação de briquetes e fertilizantes; Fabricação de 'pequenos objetos de madeira', que são definidos como pequenas peças confeccionadas de modo industrial ou artesanal que podem ser manuseadas ou conduzidas facilmente com as mãos. Os chamados 'pequenos objetos de madeira', também conhecidos como POM, têm grande 
importância no cotidiano das pessoas. Estão presentes nos mais diversos tipos: artigos domésticos de caráter utilitário e decorativo, complemento de outros materiais, artigo de uso pessoal, brinquedos e artigos esportivos.

Sugere-se que, em cada aproveitamento proposto, seja realizado um estudo detalhado visando o maior retorno econômico e também menor risco ambiental, devido à geração de resíduos nocivos ao meio ambiente. Para a marcenaria em questão, esse retorno econômico seria tratado como racionalização de despesa, devido à mesma ser uma instituição pública sem fins lucrativos.

\section{CONCLUSÕES}

Este trabalho buscou a caracterização e quantificação dos resíduos madeireiros do processo produtivo de uma oficina de marcenaria pertencente ao Tribunal de Justiça de Pernambuco, cuja atividade principal é a fabricação de móveis sob encomenda. Os móveis confeccionados consistem em birôs (25\%), armários $(25 \%)$, gaveteiros $(25 \%)$, estações de trabalho $(12,5 \%)$ bancadas de serviço $(12,5 \%)$ os quais se destinam exclusivamente para os departamentos diversos que compõem o TJPE.

Para essa busca foi feita uma análise do atual gerenciamento desses resíduos, e verificou-se que o modelo atual era de destinação adequada, ou seja, os resíduos eram doados para uma cooperativa, a qual destinava $41,18 \%$ para fornos e padarias, $41,17 \%$ forração para criação de frangos e 17,65\% para consumo doméstico, conforme informações repassadas durante a entrevista com o responsável pela marcenaria, onde foi também constatado que todos envolvidos no setor demonstraram uma baixa percepção referente aos danos que podem ser causados ao meio ambiente e à saúde pública em decorrência da utilização inadequada dos resíduos dessa atividade, mesmo que em pequena escala. Nessa perspectiva, ficou claro que a baixa percepção dos riscos ao meio ambiente está atrelada à falta de capacitação dos que fazem parte deste setor.

Porém, apesar da doação, faltavam ações sustentáveis no que diz respeito ao aumento da eficiência no uso da matéria-prima, visando à diminuição desses resíduos, cujo gerenciamento deve ser realizado não apenas com a finalidade de proteger o meio ambiente, mas também com o intuito de diminuir o desperdício de matéria-prima. Portanto, é através da avaliação do processo produtivo, sem perder o foco no impacto ambiental do ciclo de vida do produto, que deve ser tomada as decisões no tocante ao gerenciamento de resíduos tanto nas marcenarias quanto nas indústrias moveleiras. Neste contexto, o domínio do conhecimento desses resíduos tem importância fundamental no âmbito social, econômico e ambiental. Vale, ainda, ressaltar que os resíduos derivados da madeira são classificados pela Política Nacional de Resíduos Sólidos (PNRS) quanto à origem, como resíduos industriais e, quanto à periculosidade, pela NBR 10.004/2004, como classe II-A, não perigosos, assim considerados por não apresentarem contaminação por vernizes, tintas, colas ou outras substâncias; e não inertes, por possuírem propriedades de biodegradabilidade, combustibilidade ou solubilidade em água. A identificação e a classificação correta dos resíduos permitem uma avaliação mais acurada do gerenciamento de resíduos sólidos, de modo a verificar a conformidade com a legislação vigente.

As causas da geração dos resíduos estavam relacionadas à falta de adoção de medidas preventivas, 
tais como: manutenção periódica dos equipamentos utilizados em toda cadeia produtiva, afiação dos discos de corte, troca de peças desgastadas, além de carência no que diz respeito à capacitação dos colaboradores. Vale, ainda, destacar, que as máquinas que apresentaram maior quantidade de resíduos madeireiros foram a plaina e a lixadeira.

Com referência à quantificação dos resíduos sólidos de madeira gerados, levantou-se um total estimado em 1,80 toneladas por ano, sendo à maior parte formada por retraços (33,3\%), serragem (33.3\%), cavaco $(16.67 \%)$ e maravalha $(16,67 \%)$. Sendo assim, considerando-se que são utilizados, aproximadamente, 7,34 toneladas de matéria-prima por ano, a marcenaria apresenta um percentual de perda de $24,5 \%$, o que significa que esse percentual da matéria-prima que entra no processo produtivo não é utilizado e se transforma em resíduo sólido e esse, por sua vez, passa a ser considerado desperdício. Tendo em vista esses aspectos, é de suma importância que a instituição inclua no seu Plano de Logística Sustentável (PLS) a preocupação com a mitigação e destino final dos resíduos madeireiros gerados durante a confecção dos móveis.

Ressaltamos a necessidade de estudos mais detalhados sobre o aproveitamento de resíduos madeireiros dentro da marcenaria estudada, para que ela possa agregar valores aos seus produtos, buscando maiores retornos econômicos, visando racionalizar suas despesas.

Diante disso, alternativas foram propostas para viabilizar o uso racional dos resíduos madeireiros gerados pela oficina do TJPE, sobretudo referente à produção de novos produtos, como briquetes e fertilizantes e também para a fabricação de pequenos objetos de madeira.

\section{REFERÊNCIAS}

ALVES, R.; SOUZA, A. S; REIS, A. R. S.. Diagnóstico laboral e quantificação de resíduos madeireiros no município de Monte Alegre-PA: um estudo de caso. Monografia (Bacharelado) - Universidade Federal do Pará, Altamira, 2014.

ABNT. Associação Brasileira de Normas Técnicas. NBR 10.004:2004: Resíduos Sólidos: Classificação. Rio de Janeiro: ABNT, 2004.

CAETANO, M. D. D. E.. Análise do gerenciamento de resíduos sólidos em micro e pequenas empresas do setor de móveis de madeira da grande Vitória-ES. Tese (Doutorado em Engenharia de Desenvolvimento Sustentável) - Universidade Federal do Espírito Santo, Vitória, 2017.

CAETANO, M. D. D. E.; DEPIZZOL, D. B.; REIS, O. P.. Análise do gerenciamento de resíduos sólidos e proposição de melhorias: estudo de caso em uma marcenaria de CariacicaES. Gest. Prod., São Carlos, v.24, n.2, p.382-394, 2017.

GOMES, C. M.; KNEIPP, J. M.; KLUGLIANSKAS, I.; ROSA, L. A. B.; BICHUETI, R. S.. Management for sustainability: Ananalysis of the key practices according to the business size. Ecológica Indicators, v.52, p.116-127, 2015. DOI: http://dx.org/10.1016/i.Ecolind.2014.11.012

HILLIG, É.; SCHNEIDER, V. E.; PAVONI, E. T.. Geração de resíduos de madeira e derivados da indústria moveleira em função das variáveis de produção. Produção, v.19, n.2, p.292-303, 2009.

LOPES, M. A.. Gerenciamento de resíduos madeireiros em pequenas indústrias de produtos de madeira de maior valor agregado. Dissertação (Mestrado em Recursos Florestais) - Universidade de São Paulo, Piracicaba, 2016.

MAFFESSONI, D.; MENEGUZZI, Á.. Diagnóstico da gestão dos resíduos de madeira e de chapas nas indústrias do Polo Moveleiro de Bento Gonçalves. In: CONGRESSO INTERNACIONAL DE TECNOLOGIAS PARA O MEIO AMBIENTE, 3. Anais. Bento Gonçalves, 2012.

MENDOZA, Z. M. S. H.; EVANGELISTA, W. V.; ARAÚJOS, S. O.; SOUZA, C. C.; RIBEIRO, F. D. L.; SILVA, J. C.. Análise dos resíduos madeireiros gerados nas marcenarias no município de Viçosa - Minas Gerais. Revista Árvore, Viçosa, v.34, n.4, p.755-760, 2010.

NASCIMENTO, N. C.. Geração de resíduos em uma indústria de móveis de médio porte. Dissertação (Mestrado) Universidade de Ribeirão Preto, Ribeirão Preto, 2009.

NOLASCO, A. M.; ULIANA, L. R.. Gerenciamento de resíduos na indústria de pisos de madeira. Piracicaba: ANPM, 2014.

SANTOS, L. S.. Análise de geração de resíduos na 
marcenaria da Universidade Federal de Sergipe (UFS)

Monografia (Bacharelado) - Universidade Federal de

Sergipe, São Cristóvão, 2017.
SEBRAE. Serviço Brasileiro de Apoio às Micro e Pequenas Empresas. Comércio e serviços: Madeira e móveis planejados. SEBRAE, 2017.

A CBPC - Companhia Brasileira de Produção Científica (CNPJ: 11.221.422/0001-03) detém os direitos materiais desta publicação. Os direitos referem-se à publicação do trabalho em qualquer parte do mundo, incluindo os direitos às renovações, expansões e disseminações da contribuição, bem como outros direitos subsidiários. Todos os trabalhos publicados eletronicamente poderão posteriormente ser publicados em coletâneas impressas sob coordenação da Sustenere Publishing, da Companhia Brasileira de Produção Científica e seus parceiros autorizados. Os (as) autores (as) preservam os direitos autorais, mas não têm permissão para a publicação da contribuição em outro meio, impresso ou digital, em português ou em tradução. 